\title{
Entrenchment or Enhancement: Could Climate Change Adaptation Help to Reduce Chronic Poverty?
}

\author{
Thomas Tanner and Tom Mitchell'
}

\begin{abstract}
1 Introduction and overview
How to tackle climate change impacts in the context of sustainable development and poverty reduction is becoming a major and pressing concern in many parts of the world. Having moved from the realms of environmental debate to major development fora, climate change was billed in the recent UK International Development White Paper as the 'biggest threat facing the world' (DFID 2006). While efforts to mitigate the rate and extent of climate change by limiting greenhouse gas emissions are a crucial component of our response, two driving factors are clear. First, that whatever stabilisation or reduction in emissions we achieve, we are already bound into some change by existing atmospheric greenhouse gas concentrations locked into the system. Second, anomalous and extreme weather events have increased in recent decades in ways consistent with modelling projections, indicating that climate change is already happening (IPCC 2007a,b).
\end{abstract}

The impacts of both gradual climate change and extreme weather events are already being felt on the ground and are differently distributed across different parts of human society (Smit et al. 2001). Mounting evidence and the prevailing discourse suggests that without dramatic policy interventions, existing and future climate impacts will frustrate pathways out of poverty (DFID 2006; IPCC 2007b). This discourse frequently cites the poorest people in the world as having the least capacity to adapt to a changing climate, lacking the assets, social networks, mobility, and political power, commonly cited as being critical for adaptation (ADB et al. 2003).

However, the assertion that the poorest communities are the most vulnerable to climate change is commonly made as a generalisation, with limited examination of the dynamic and differentiated nature of poverty. This article aims to unpack this orthodoxy through an examination of the climate change and chronic poverty literature, thereby creating the case for a more nuanced understanding of poverty for vulnerability and adaptation to climate change. Through such an understanding, the article suggests ways in which climate change may actually be an opportunity to create pathways out of chronic poverty through targeted efforts to enhance vulnerability reduction and adaptation. Finally, it develops a set of research questions and a vision for the collaborative framework needed to propose a pioneering research and policy agenda on pro-poor adaptation.

\section{Adaptation and chronic poverty: bringing together the communities 2.1 Climate change, poverty and adaptation} The Fourth Assessment Report (AR4) of the Intergovernmental Panel on Climate Change (IPCC), states unequivocally that the global climate is warming. Both Africa and South Asia have been identified as two of the most vulnerable regions to both current variations in climate (climate variability) and future climate change (Nkomo et al. 2006; IPCC 2007b). Within Africa, projected temperature increases of $0.2-0.5^{\circ} \mathrm{C}$ per decade (Commission for Africa 2005) are likely to adversely affect livelihoods through impacts upon agricultural production, biodiversity and food and water security. Similarly, in South Asia crop yields are projected to decrease by up to 30 per cent by the mid-twenty-first century (IPCC 2007b), severely impacting food security. Alongside flooding from Himalayan glacial melt, highly populated coastal areas are seen to be at 
Figure 1 Potential impacts of climate change on poverty and the MDGs

\section{Changes in mean \\ climate, variability, \\ extreme events and \\ sea-level rise}

Increased temperature

and changes in

precipitation reduce

agricultural and

natural resources

Change in precipitation, run-off and variability leads to greater water stress

Increased incidence or intensity of climaterelated disasters leads to damage to assets and infrastructure

Temperature, water and vegetation changes contribute to increased prevalence of disease
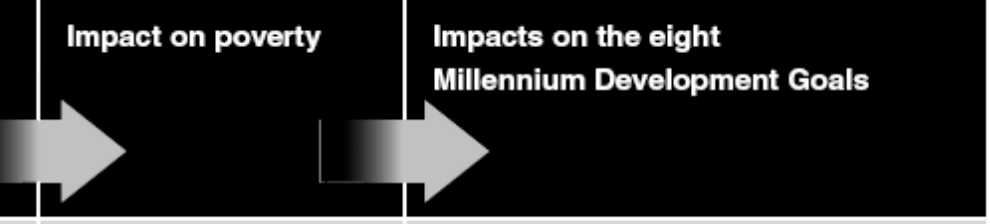

Lowered industrial output and labour productivity, high inequality, impacts on trade, and fiscal and macro-economic burdens lead to reduced economic growth, and povertyreducing effects

Reduced productivity and security of poor people's livelihood assets, and reduced access for the poor to their livelihood assets

Less effective coping strategies among the poor, and increased vulnerability of poor people by disasters.
1 Eradicate extreme poverty and hunger

Food security jeopardised; more intense disasters threaten livelihoods.

2 Achieve universal primary 2 education

More vulnerable livelihoods mean more children engaged in employment; infrastructure damage from disasters.

3 Promote gender equality and 3 empower women Women make up two-thirds of world's poor and are more adversely impacted

\section{Reduce child mortality \\ Children more vulnerable to malaria} and other diseases, which are spread more widely by climate change.

5 Improve maternal health 5 Pregnant women particularly susceptible to malaria.

6 Combat HIVIAIDS, malaria and other diseases

Increased prevalence of mosquito-borne diseases.

7 Ensure environmental sustainability

Climate change indication of unsustainable practices. Move towards more energy-efficient models of consumption.

Promote global partnerships

Wider forums must acknowledge the role of climate change in impacting MDGs. 
Figure 2 Categories of poverty

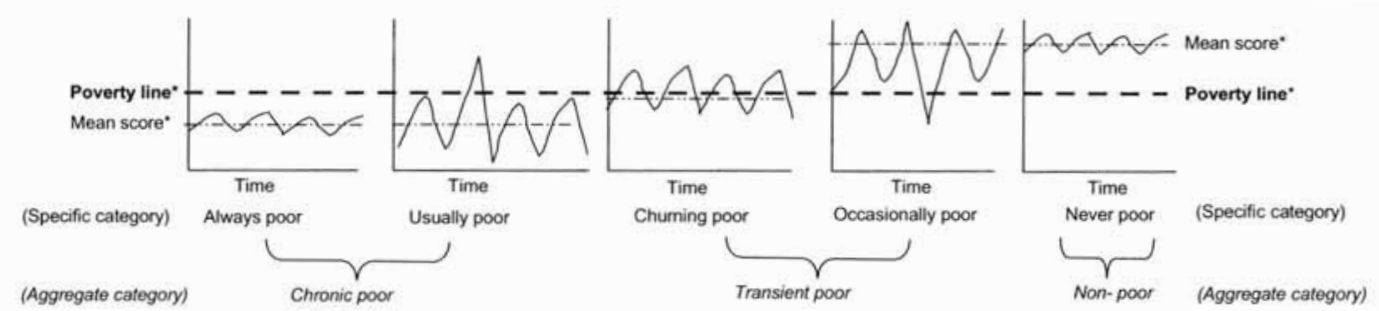

Depending on data availability poverty could be assessed in terms of household expenditure, income, consumption, a nutritional measure,

a poverty index, a poverty scale or an assessment of assets/capitals.

Source Hulme et al. (2001).

greatest risk from increased flooding from the sea and, in some mega-deltas, flooding from the rivers (IPCC 2007b).

The impacts of climate change are not evenly distributed, in part due to the differentiated nature of hazards in different parts of the globe, but also due to differences in the ability to cope with and adapt to the negative effects and harness beneficial effects of climate shocks and stresses. The common generic conclusion is that those exposed to the most severe hazards are also those least able to cope with the associated impacts (Smit et al. 2001; ADB et al. 2003; Adger et al. 2003). Poverty levels are therefore important determinants of climate change impacts, which in turn pose multiple threats to the achievement of the Millennium Development Goals (MDGs) (Figure 1).

In the face of these challenges, a growing body of work and international implementation has formed around adapting systems to prepare for and respond to climate change. Known as adaptation, this is defined by the IPCC (2001) as:

Adjustment in natural or human systems in response to actual or expected climatic stimuli or their effects, which moderates harm or exploits beneficial opportunities.

Early approaches to adaptation were based on modelling to project future climate changes and secondary impacts (e.g. on crops and water availability). This then provides the basis for decisions on how to adapt to cope with this given change (McCarthy et al. 2001). Although able to be applied to wide areas and provide quantified estimates for decision-makers, such approaches are complicated by the inherent uncertainty of predictions, and a tendency to ignore wider factors affecting vulnerability to climate change (Klein et al. 2007).

An emerging alternative approach has developed which provides resilience to future changes by building on improving the ability to cope with existing variations in climate (Burton and van Aalst 2004). Drawing more heavily on field assessments of existing vulnerability and coping mechanisms to climate variations (Mitchell and Tanner 2006), this approach is able to take measures to address the underlying causes of vulnerability to climate change, such as structural factors that can cause and entrench poverty, including poor access to natural resources or services (ADB et al. 2003; Klein et al. 2007).

\subsection{Defining chronic poverty}

There are up to 420 million chronically poor people in the world and the majority live in South Asia and sub-Saharan Africa (CPRC 2007). In most cases, chronic poverty is defined as the deepest level of poverty where some are always or usually poor because their income expenditure/consumption is below the poverty line (Jalan and Ravallion 2000). Whereas some authors have focused on the duration spent below the poverty line, others have differentiated the poor further by separating the 'very poor' (those with no apparent prospects of reversing the downward trend in their livelihood) from 'poorbut-coping' households (those who are able to sustain their livelihoods but who are intermittently vulnerable to a downward spiral of their livelihood) (Cleaver 2005). Figure 2 depicts various types of poverty. 
Income and levels of consumption are commonly used as metrics to understand and define chronic poverty, enabling quantification and cross-

comparison. However, this limits understanding of the multidimensional nature of chronic poverty and has led to greater exploration of the social and political factors that describe and explain chronic poverty. These examine why chronic poverty occurs based on the lack of basic assets, entitlements and capabilities (Sen 1999). These capabilities are usually measured at the household level and include education, health, human and civil rights (Hulme and Shepherd 2003). Mutual reinforcement is at play: a lack of capabilities worsens chronic poverty and being chronically poor also limits capabilities.

\subsection{Vulnerability, poverty and climate change} Vulnerability is a key concept linking research and discourse around chronic poverty and climate change adaptation, however it can be conceptualised along both ecological and social lines. From an ecological perspective, vulnerability can be understood through the frequency and magnitude of a system's response to an external event, such as a hazard, defined in poverty terms as a risk of inability to cope with a shock, leading to catastrophe (Hulme and Shepherd 2003).

This approach takes different shocks and stresses, such as ill health, economic collapse and natural disasters (CPRC 2007), as the basis for studying vulnerability. In addition to shocks, people can be adversely affected by trends such as gradual environmental degradation, oppressive political systems or deteriorating terms of trade (IISD 2003). Barrientos (2007) notes that for such approaches, it is the depth, strength or repeated nature of the shocks that lead to chronic poverty.

This perspective is also reflected in the systems approach of the IPCC (McCarthy et al. 2001), which defines vulnerability as:

The degree to which a system is susceptible to, or unable to cope with, adverse effects of climate change, including climate variability and extremes. Vulnerability is a function of the character, magnitude, and rate of climate variation to which a system is exposed, its sensitivity, and its adaptive capacity.

The IPCC's definition reflects a natural science-driven conception of vulnerability as the residual effect of a given climate impact after any adaptation activities are undertaken. This tends to favour technical issues in analysis and development of adaptation solutions, for example focusing on the provision of weather forecasting information (Klein et al. 2007).

Increasingly however, social approaches to vulnerability stemming from the poverty literature have become influential. In conceiving of vulnerability as representing a general set of characteristics influencing the capacity to adapt and respond to shocks and stresses, the ability to cope with shocks is seen as depending on a wide range of factors in relation not only to the nature of shocks but also the characteristics of a population and assets people possess. In general, the less one possesses assets such as education, health and social networks (Adger et al. 2004), the greater the likelihood that vulnerability is high, with greater likelihood that shocks and stresses will lead to chronic poverty.

This social conception of vulnerability emphasises the need to take broader elements of vulnerability into account, such as human security, empowerment, corruption, or access to natural resources (Swift 1989; Yamin et al. 2005; Klein et al. 2007). More recently, there has been increasing examination of resilience as a concept applicable to both ecological and social systems (Adger 2000; Gallopin 2006; Tompkins and Adger 2004; www.steps-centre.org; www.resalliance.org). The poverty literature cites building resilience as a means of reducing vulnerability in terms of the ease and rapidity of a system's response to an external event (Moser 1998; Scott 2006). Similarly, climate change researchers have identified characteristics of resilient societies and applied these to adaptation, including the ability to buffer disturbance, to self organise, and to learn and adapt (Tompkins and Adger 2004; Tanner et al. 2007b; Lemos and Tompkins, this IDS Bulletin). Resilience therefore encapsulates people's assets, but also the services provided to them by external infrastructure and the networks of societal and institutional relationships to which they have access (IISD 2003; Prowse and Scott, this IDS Bulletin).

\section{Linkages and challenges: climate change and chronic poverty}

Having introduced the two fields, we now highlight some of the linkages and challenges raised by each of the two fields. We argue that despite advances informed by diverse ideologies in linking poverty and 


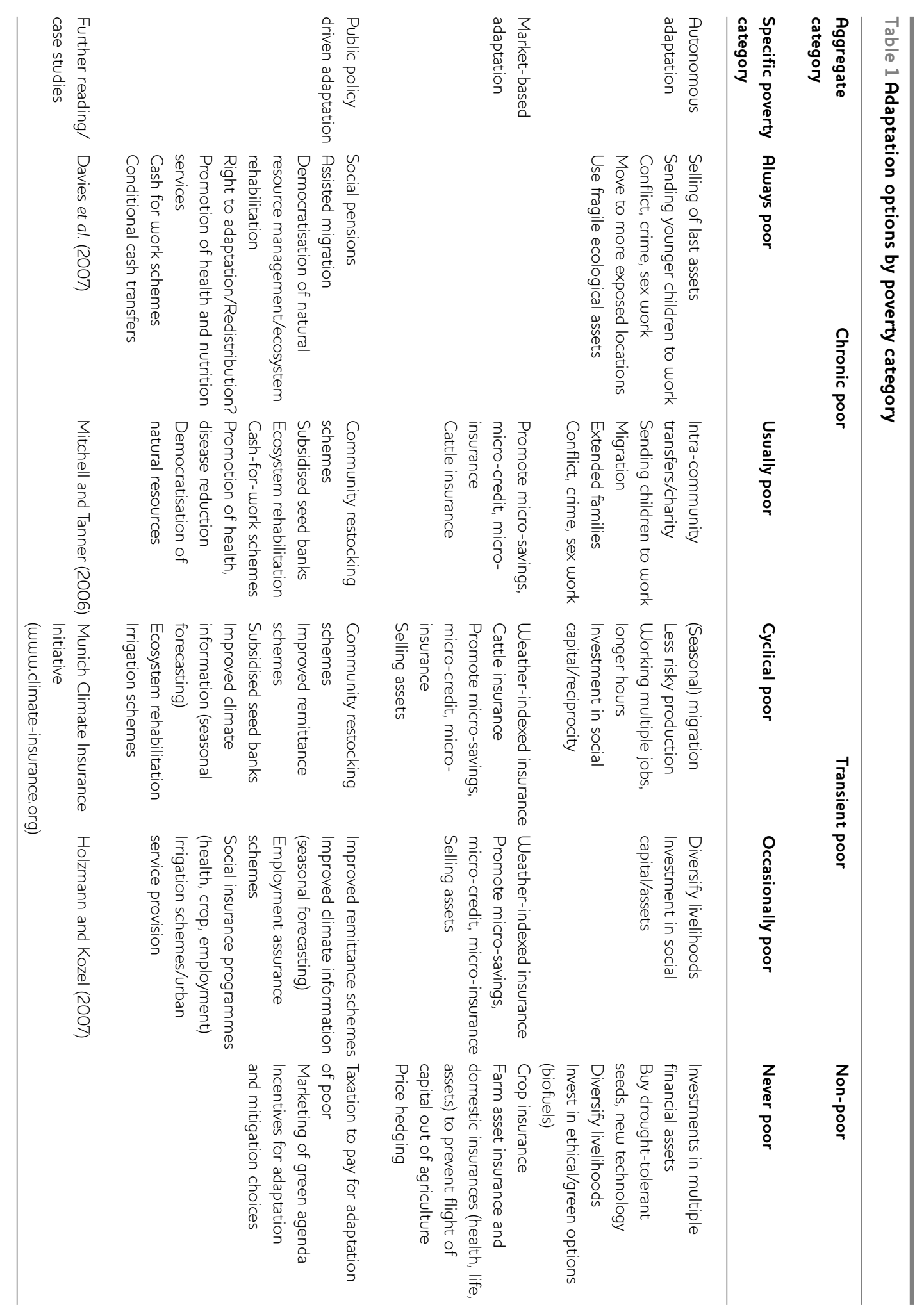

10 Tanner and Mitchell Entrenchment or Enhancement: Could Climate Change Adaptation Help to Reduce Chronic Poverty? 
climate change adaptation, much analysis and rhetoric in the climate change community remains around an undifferentiated poor with the community as unit of analysis. We then go on to suggest ways for engaging chronic poverty with adaptation debates and practices in the future, and the research implications for doing so.

\subsection{Ideological drivers linking poverty and adaptation}

To date, the principal interplay between the two fields has been through analysis and projections on the extent to which climate change impacts will perpetuate or deepen poverty across the world. Such analyses, through stressing the disproportionate effect of climate change on poor communities relative to richer communities through loss of assets, lives and repeated shocks (McCarthy et al. 2001; IPCC 2007b; ADB et al. 2003; Commission for Africa 2005; DFID 2006; Stern 2006) has driven advocacy campaigns around the need to reduce greenhouse gas emissions to levels that will avoid dangerous levels of human-induced climate change (Simms and Reid 2004). Increasingly however, it has become apparent that poor people are already, and will continue to be, at the forefront of exposure to extreme weather events and the impacts of climate change. Within the development community this has driven a growing momentum for improving the capacity of developing country government and poor communities themselves to manage and adapt to impacts today and in the future.

This growing momentum for adaptation has been informed by different sets of ideological drivers, with different implications for engagement with chronic poverty debates. Within both, there remains a strong imperative to provide the evidence base regarding the impact of changing climate on poor people. In particular, this informs the negotiations around international climate change adaptation agreements and funds in order to focus adaptation on achievement of the MDGs and targeting the most vulnerable communities.

Instrumental effectiveness has been the principal driver in the World Bank and many donor cooperation agencies in shaping approaches to tackling adaptation through development of risk management approaches (Burton and van Aalst 2004; Tanner et al. 2007a). Here, economic analysis is used to build a case for adaptation as a cost-effective process of preventing future negative impacts on development investments (Stern 2006), and ensuring that development finance is effective in meeting targets for poverty reduction, including the MDGs. Development agencies have operationalised this approach through the screening of programmes and projects to assess current and future climate sensitivity and risk, building in adaptation to development project design in a risk management framework (Klein et al. 2007; Tanner et al. 2007a).

At the same time, approaches to adaptation are also informed by equity and justice dimensions of the issue of human-influenced climate change. This presents adaptation in poor communities as a necessary response to a problem caused by the richer sections of society across the world but with impacts felt most severely by poorer members who have contributed least to the problem (Paavola and Adger 2006). This has formed the backbone of adaptation as an advocacy and campaigns issue, particularly among international non-governmental organisations (NGOs) (Simms and Reid 2004; Christian Aid 2006).

Where informed by equity and justice ideology, the need to tackle adaptation in the context of chronic poverty is therefore considered a moral necessity, with new and additional finance for adaptation being provided by richer parts of the global community, who are those primarily responsible for the problem. This finance should target the poor and most vulnerable globally, those both most reliant on climate sensitive resources, living in the most marginal environments, and with the least resources to cope with shocks and adapt to stresses and change (Christian Aid 2006; Mitchell and Tanner 2006). In necessarily focusing initially on this division of rights and responsibilities between rich and poor, particularly at an international level, this approach has yet to narrow down subdivisions of poverty or target the chronically poor, instead taking a broader community-based view of vulnerability and adaptation (Huq 2007).

Although there are grounds for both these ideological strands to focus on chronic poverty dimensions of adaptation, there has been limited progress in doing so to date. Some attention has been given to examining how poverty characteristics influence vulnerability (Adger 2006), but little engagement on poverty dimensions within the theory, process and practice of adaptation. Instead, 
they describe general conditions in which vulnerable people have been able to improve their capacity to manage climate impacts and adapt to future change in general terms, and at most at community level (Yamin et al. 2005).

\subsection{Poverty-centred adaptation: pathways out of poverty}

While strong drivers for a poverty-centred adaptation approach therefore exist from both ideological standpoints, there is an urgent need to provide an improved understanding of how different dimensions of poverty influence the design and implementation of adaptation processes and projects. As a first step, Table 1 highlights how different adaptation processes might be more or less suited to different categories in the poverty continuum (Jalan and Ravallion 2000; Davies et al. 2007).

A poverty-centred approach to adaptation also seeks to assess how climate change may affect routes in and out of chronic poverty due to differences in the necessary assets and access considered to be key components of adaptive capacity. This will need to ask whether climate change-related vulnerabilities will render poor people's coping mechanisms inadequate or how for others climate change may present an opportunity to chart a pathway out of chronic poverty. Changes to some ecosystems may render them more productive and offer a greater range of environmental assets (IPCC 2007b). We go further, suggesting that increasing streams of adaptation finance, where targeted at the poorest groups and where accompanied by broader institutional strengthening and attention to the drivers of vulnerability could provide a significant opportunity (echoed by Vernon, this IDS Bulletin). Considering climate change as an opportunity for the chronically poor also presents intellectual and practical challenges around a hypothesis that a lower level of assets make the chronically poor in a position of strength regarding their willingness and ability to be flexible in their livelihoods strategies.

Assessing these opportunities to make adaptation effective for the chronically poor will require moving beyond analysis at the broad community level to examine not only the location and asset context of communities, but also how vulnerability varies within locations according to socioeconomic characteristics that include the multidimensional aspects of deprivation. By focusing attention on the household, it will be possible to increase understanding of the transfer and uptake of adaptive practices and provide a more nuanced appreciation of how households take decisions about risks based on climate information (Thomas et al. 2005).

\subsection{Potential testing grounds for poverty-centred adaptation}

In developing a poverty-centred adaptation approach, we briefly touch on three potential analytical lenses for research into chronic povertyadaptation linkages, starting with social protection. Encompassing a broad range of centrally and locally planned measures covering income and asset transfer to enhance rights of the marginalised, climate change poses many questions for the design of social protection programmes (Barrientos 2007; Devereux and Sabates-Wheeler 2007). For example, does climate change impose an asset threshold, beyond which adaptation becomes impossible, and beyond which social protection measures cannot be successful? Does climate change require different approaches to social protection or is business as usual just as effective? The article by Davies et al. (this IDS Bulletin) addresses these and other issues.

Another lens is provided by insecurity. Recent research clearly suggests that violent conflict plays a central role in creating and sustaining chronic poverty (Goodhand 2001; Justino 2006). Purvis and Busby (2004) suggest the relatively slow pace of climate change means it is likely to be the invisible, but not the primary, cause of armed conflict. More conflicts, added to drought, disease and the potential for economic stagnation and humanitarian crises linked to climate change, may contribute to the growing fragility of states (Smith 2007). Given the lack of empirical analysis on the nexus between climate change and security, one potentially fruitful avenue of research would be to view climate change as an opportunity in a fragile state context to build flexible and chaotic institutions that may be better suited to the challenge of adapting to climate change (Pelling and High 2005).

Linkages between migration, chronic poverty and climate change also lack detailed exploration. If forced migration increases, improving our understanding regarding the influence of climatic factors on migratory flows relative to other influencing factors among the chronically poor would enable proactive measures to facilitate migratory flows among the poor, enhance 
opportunities and limit negative effects on chronically poor people.

\section{Conclusion: critical areas for linking adaptation chronic poverty}

This article acknowledges that the impacts of climate change are already being realised and are likely to be most severe in Africa and South Asia, two regions with the highest concentrations of chronically poor people. To avoid a rapid growth in the number of chronically poor, research on the specific design of institutional support mechanisms, such as social protection, conflict prevention and service delivery must accompany the work on climate change impacts. While shocks are likely to increase in frequency and magnitude, so is the funding available for institutional support. Proactive adaptation therefore has the potential to provide an opportunity to move people out of chronic poverty. To achieve this goal requires improving our understanding of the interrelationships between poverty, vulnerability and adaptation in order to design and tailor adaptation measures with the needs of the chronically poor in mind.

In conclusion, this article points to a need for a new poverty-centred adaptation research agenda. We

\section{Note}

* This article is based on a working paper for the Chronic Poverty Research Centre (Tanner and Mitchell 2008). We would like to express our

\section{References}

Adger, W.N. (2006) 'Vulnerability', Global Environmental Change 16.1: 268-81

Adger, W.N. (2000) 'Social and Ecological Resilience: Are They Related?', Progress in Human Geography 24.3: 347-64

Adger, W.N.; Brooks, N.; Bentham, G.; Agnew, M. and Eriksen, S. (2004) New Indicators of Vulnerability and Adaptive Capacity, Tyndall Technical Report 7, Norwich: Tyndall Centre for Climate Change Research

Adger, W.N.; Huq, S.; Brown, K.; Conway, D. and Hulme, M. (2003) 'Adaptation to Climate Change in the Developing World', Progress in Development Studies 3.3: 179-95

ADB (African Development Bank); Asian Development Bank; Department for International Development: suggest a range of fruitful areas for research areas, many of which are picked up by the articles in this IDS Bulletin:

- Understanding that vulnerabilities and adaptation options may change according to different poverty categories

- Conducting household level analysis to facilitate a more targeted approach appropriate for households in different poverty categories

- Investigating the adaptive flexibility of the chronically poor

- Developing the evidence base for designing adaptation programmes that target different poverty categories

- Developing a pro-poor adaptation agenda for adoption in future international agreements, particularly to ensure pro-poor adaptation financing

- Investigating adaptive institutional and legal structures that can respond to current and future climate risks by reducing vulnerabilities of the chronic poor

- Linking scientific modelling with a deeper understanding of the impacts of climate change on shifting people into and out of poverty.

sincere thanks to Moushumi Chaudhury for preparing initial inputs for this paper and to Armando Barrientos and colleagues at CPRC for comments and feedback.

United Kingdom; Directorate-General for International Cooperation: the Netherlands; Directorate General for Development: European Commission; Federal Ministry for Economic Cooperation and Development: Germany; Organisation for Economic Co-operation and Development; United Nations Development Programme; United Nations Environment Programme; World Bank (2003) Poverty and Climate Change: Reducing the Vulnerability of the Poor Through Adaptation, www.undp.org/energy/ povcc.htm (accessed 8 July 2008)

Barrientos, A. (2007) Does Vulnerability Create Poverty Traps?, Working Paper 76, Manchester: Chronic Poverty Research Centre (CPRC)

Burton, I. and van Aalst, M. (2004) Look Before You Leap: A Risk Management Approach for 
Incorporating Climate Change Adaptation in World Bank Operations, Washington DC: World Bank Christian Aid (2006) The Climate of Poverty: Facts, Fears and Hopes, www.christianaid.org.uk/lmages/ climate_of_poverty_tcm15-21613.pdf (accessed 9 July 2008)

Cleaver, F. (2005) 'The Inequality of Social Capital and the Reproduction of Chronic Poverty', World Development 33.6: 893-906

Commission for Africa (2005) Our Common Interest: Report of the Commission for Africa, www.commissionforafrica.org/english/report/ introduction.html (accessed 8 July 2008)

CPRC (2007) 'Chronic Poverty: An Introduction', Policy Brief 1, Manchester: Chronic Poverty Research Centre

Davies, M.; Mitchell, T.C.; Slater, R. and Peskett, L. (2007) 'Can Cash Combat Climate Change? Adaptation and Social Protection', presentation to DFID Environment Adviser's Retreat, Wyboston Lakes, July 2007, www.ids.ac.uk/UserFiles/File/ poverty_team/climate_change/Can_Cash_Combat _Climate_Change_4_July_07.ppt (accessed 9 July 2008)

Devereux, S. and Sabates-Wheeler, R. (eds) (2007) 'Debating Social Protection', IDS Bulletin 38.3: 1-7

DFID (2006) 'Working Internationally to Tackle Climate Change', in Eliminating World Poverty: Making Governance Work for the Poor, White Paper on International Development, London: Department for International Development, Ch. 7, www.dfid.gov.uk/pubs/files/whitepaper2006/ wp2006section4.pdf (accessed 8 July 2008)

DFID (2004) Climate Change and Poverty, Keysheet 1 , www.dfid.gov.uk/pubs/files/climatechange/lpover tyPRS.pdf (accessed 8 July 2008)

Gallopin G.C. (2006) Linkages Between Vulnerability, Resilience, and Adaptive Capacity, Global Environmental Change 16.3: 235-316

Goodhand, J. (2001) Violent Conflict, Poverty and Chronic Poverty, CPRC Working Paper 6, Manchester: Chronic Poverty Research Centre

Holzmann, R. and Kozel, V. (2007) 'The Role of Social Risk Management in Development: A World Bank View - Reply to Comments', IDS Bulletin 38.3: 20-2 Hulme, D. and Shepherd, A. (2003) 'Conceptualizing Chronic Poverty', World Development 31.3: 403-23

Hulme, D.; Moore, K. and Shepherd, A. (2001) Chronic Poverty: Meanings and Analytical Frameworks, CPRC Working Paper 2, Chronic Poverty Research Centre, www.chronicpoverty.org/pubfiles/ 02Hulme_et_al.pdf (accessed 5 August 2008)
Huq, S. (2007) Community Based Adaptation: An IIED Briefing Note, London: International Institute for Environment and Development

IISD (2003) Livelihoods and Climate Change, Manitoba: International Institute for Sustainable Development

IPCC (Intergovernmental Panel on Climate Change) (2007a) Contribution of Working Group I to the Fourth Assessment Report of the Intergovernmental Panel on Climate Change: The Physical Science Basis Summary for Policymakers, www.ipcc.ch/ ipccreports/ar4-wg1.htm (accessed 8 July 2008)

IPCC (2007b) Contribution of Working Group II to the Fourth Assessment Report of the Intergovernmental Panel on Climate Change: Impacts, Adaptation and Vulnerability Summary for Policymakers, www.ipcc.ch/ ipccreports/ar4-wg2.htm (accessed 8 July 2008)

IPCC (2001) Climate Change 2001: Working Group II: Impacts, Adaptation and Vulnerability, www.grida.no/ climate/ipcc_tar/wg2/index.htm (accessed 8 July 2008)

Jalan, J. and Ravallion, M. (2000) 'Is Transient Poverty Different? Evidence for Rural China', Journal of Development Studies 36.6: 82-99

Justino, P. (2006) On the Links Between Violent Conflict and Chronic Poverty: How Much Do We Really Know?, CPRC Working Paper 6, Manchester: Chronic Poverty Research Centre Klein, R.T.J.; Eriksen, S.E.H.; Næss, L.O.; Hammill, A.; Tanner, T.; Robledo, C. and O'Brien, K.L. (2007) Portfolio Screening to Support the Mainstreaming of Adaptation to Climate Change into Development Assistance, Tyndall Centre Working Paper 102, Norwich: Tyndall Centre

McCarthy, J.; Canziani, O.F.; Leary, N.A.; Dokken, D.J. and White, K.S. (eds) (2001) Climate Change 2001: Impacts, Adaptation, and Vulnerability, Cambridge: Cambridge University Press

Mitchell, T. and Tanner, T.M. (2006) Adapting to Climate Change: Challenges and Opportunities for the Development Community, Teddington: Tearfund

Moser, C. (1998) 'The Asset Vulnerability Framework: Reassessing Urban Poverty Reduction Strategies', World Development 26.1: 1-19

Nkomo, J.C.; Nyong, A. and Kulindwa, K. (2006) The Impacts of Climate Change in Africa, report prepared for the Stern Review, www.hm-treasury.gov.uk/ independent_reviews/stern_review_economics_ climate_change/stern_review_supporting_ documents.cfm (accessed 8 July 2008)

Paavola, J. and Adger, W.N. (2006) 'Fair Adaptation to Climate Change', Ecological Economics 56: 594-609 
Pelling, M. and High, C. (2005) 'Understanding Adaptation: What can Social Capital Offer Assessments of Adaptive Capacity?', Global Environmental Change A, 15.4: 308-19

Purvis, N. and Busby, J. (2004) 'The Security Implications of Climate Change for the UN System', Environmental Change and Security Project Report Issue 10

Scott, L. (2006) Chronic Poverty and the Environment: A Vulnerability Perspective, CPRC Working Paper 62, Manchester: Chronic Poverty Research Centre

Sen, A.K. (1999) Commodities and Capabilities, Oxford: Oxford University Press

Simms, A. and Reid, H. (2004) Up in Smoke, London: New Economics Foundation

Smit, B.; Pilifosova, O.; Burton, l.; Challenger, B.; Huq, S.; Klein, R.; Yohe, G.; Adger, N.; Downing, T. and Harvey, E. (2001) 'Adaptation to Climate Change in the Context of Sustainable Development and Equity', in J.J. McCarthy, O. Canziani, N.A. Leary, D.J. Dokken and K.S. White (eds), Climate Change 2001: Impacts, Adaptation and Vulnerability. IPCC Working Group II, Cambridge: Cambridge University Press

Smith, D. (2007) 'The Double-headed Risk of Climate Change and Armed Conflict', International Alert Briefing Note, March 2007

Stern, N. (2006) The Economics of Climate Change: The Stern Review, Cambridge: Cambridge University Press
Swift, J. (1989) 'Why are Rural People Vulnerable to Famine?', IDS Bulletin 20.2: 8-15

Tanner, T. and Mitchell, T. (2008) Entrenchment or Enhancement: Could Climate Change Adaptation Help Reduce Chronic Poverty?, Working Paper 106, Manchester: Chronic Poverty Research Centre

Tanner, T.M.; Hassan A.; Islam K.M.N.; Conway, D.; Mechler, R.; Ahmed A.U. and Alam, M. (2007a) ORCHID: Piloting Climate Risk Screening in DFID Bangladesh, Research Report, Brighton: IDS

Tanner, T.M.; Mitchell, T.C.; Polack, E. and Guenther, B. (2007b) Urban Governance for Adaptation: Assessing Climate Change Resilience in Ten Asian Cities, Report to the Rockefeller Foundation, Brighton: IDS

Thomas, D.; Osbahr, H.; Twyman, C.; Adger, W.N. and Hewitson, B. (2005) Adaptations to Climate Change Amongst Natural Resource-dependant Societies in the Developing World: Across the Southern African Climate Gradient, Tyndall Centre Technical Report 35, Norwich: Tyndall Centre for Climate Change Research

Tompkins, E.L. and Adger, W.N. (2004) 'Does Adaptive Management of Natural Resources Enhance Resilience to Climate Change?', Ecology and Society 9.2: 10

Yamin, F; Rahman, A. and Huq, S. (2005)

'Vulnerability, Adaptation and Climate Disasters: A Conceptual Overview', IDS Bulletin 36.4: 1-14 